\title{
Chlamydial Infection Prevalence in Human Immunodeficiency Virus Patients
}

\author{
Feilicia Henrica Teja, ${ }^{1}$ Rasmia Rowawi, ${ }^{2}$ Asmaja Soedarwoto, ${ }^{2}$ Diah Puspitosari, ${ }^{1}$ Rini Rasianti, ${ }^{1}$ \\ Rahmatdinata, ${ }^{2}$ Tony Djajakusumah ${ }^{2}$ \\ ${ }^{1}$ Faculty of Medicine, Universitas Padjdajaran-Dr. Hasan Sadikin General Hospital \\ ${ }^{2}$ Department of Dermatology and Venereology, Faculty of Medicine, Universitas Padjajaran-Dr. Hasan Sadikin \\ General Hospital
}

\begin{tabular}{|c|c|}
\hline \multirow[t]{3}{*}{ Abstract } & $\begin{array}{l}\text { Objective: To determine the prevalence of chlamydial infection in male urethra } \\
\text { and female cervix of HIV-positive patients based on PCR assay in Teratai Clinic, } \\
\text { Dr. Hasan Sadikin General Hospital Bandung. }\end{array}$ \\
\hline & $\begin{array}{l}\text { Methods: A cross sectional observational study with consecutive sampling } \\
\text { method, which was conducted in Teratai Clinic during the month of July } 2012 \text {. } \\
\text { All participants underwent history taking, physical examination, and PCR assay } \\
\text { for } C \text {. trachomatis. Swab samples were obtained from male urethra and female } \\
\text { endocervix. }\end{array}$ \\
\hline & $\begin{array}{l}\text { Results: Eighty one HIV-positive patients, consisted of } 48 \text { males and } 33 \text { females } \\
\text { were included in this study. The PCR examination for C. trachomatis was positive } \\
\text { in } 14 \text { of } 81 \text { subjects (17.3\%), with } 10(20.8 \%) \text { urethral chlamydial infection in } 48 \\
\text { males and four (12.1\%) cervical chlamydial infection in } 33 \text { females. }\end{array}$ \\
\hline $\begin{array}{l}\text { Received: } \\
\text { January 1, } 2013\end{array}$ & $\begin{array}{l}\text { Conclusions: The study concluded that the prevalence of chlamydial infection in } \\
\text { male urethra and female cervix of HIV-positive patients were } 20.8 \% \text { and } 12.1 \% \text {, } \\
\text { respectively. Identifying chlamydial infection based on PCR testing should be } \\
\text { considered for routine screening test in HIV-positive patients. }\end{array}$ \\
\hline March 7, 2013 & Keywords: Chlamydia trachomatis, HIV, prevalence, PCR \\
\hline $\begin{array}{l}\text { Accepted: } \\
\text { May 21, } 2013\end{array}$ & IJIHS. 2013;1(1):42-8 \\
\hline
\end{tabular}

\section{Introduction}

Worldwide, Chlamydia trachomatis is one of the most common etiologies for sexually transmitted infection. ${ }^{1}$ In 2009, 92 million new cases of chlamydial infection were reported by World Health Organization, including 43 million cases in South and South-East Asia. ${ }^{2}$ Most of chlamydial infections are asymptomatic (70\% in female and $20-30 \%$ in male), ${ }^{3}$ making it difficult to diagnose clinically. ${ }^{1}$ Nowadays, polymerase chain reaction (PCR) method has been approved by the Food and Drug Administration (FDA) as the new gold standard for the diagnosis of chlamydial infection. ${ }^{4}$ In comparison with culture, the PCR method has higher sensitivity in detecting chlamydial infection (90.4\% vs $70.8 \%$ ) which makes it the best method for screening. ${ }^{5}$

\footnotetext{
Correspondence:

Feilicia Henrica Teja, Faculty of Medicine, Universitas Padjadjaran-Dr. Hasan Sadikin General Hospital

Jl. Pasteur No. 38, Bandung, Indonesia

e-mail: feilicia.t@gmail.com
}

Acquired immunodeficiency syndrome (AIDS) caused by human immunodeficiency virus (HIV) has become a great public health concern. ${ }^{6}$ In 2009, the United Nations joint program on HIV/ AIDS (UNAIDS) estimated 33.3 million cases of HIV infection with 4.1 million cases in South and South East Asia. ${ }^{7}$ Until September 2012, Indonesian Ministry of Health reported 92,251 cases of HIV infections with most of them (50.8\%) are heterosexually transmitted. ${ }^{8}$

The available epidemiological data showed that there is "epidemiological synergy" between sexually transmitted infections (STI) and HIV transmission. ${ }^{9}$ HIV transmission will increase 10 fold in STI and HIV co-infected patient ${ }^{10}$ and HIVpositive patient has higher risk of being infected with other STIs. High risk sexual behaviors and drug abuse are the two main factors causing STI and HIV co-infection. ${ }^{11}$ Both ulcerated and nonulcerated STIs may increase the risk of acquiring and transmitting HIV. ${ }^{12}$ Ulcerated STIs increase the risk of acquiring HIV 5 to 10 folds, while nonulcerated STIs increase the risk 2 to 5 folds. ${ }^{13}$ 
Although the impact of non-ulcerated STIs is smaller than ulcerated STIs, non-ulcerated STIs are more commonly found and, therefore, could also increase the HIV epidemic. ${ }^{14}$

In 2008, it was reported in a study that the prevalence of STI in HIV patients in Washington was $8 \%$ with $19.4 \%$ of them were infected by $C$. trachomatis. ${ }^{15}$ Meanwhile, in India, the prevalence of chlamydial infection in HIV patients in 2011 was 7\%. ${ }^{16}$

Sexually transmitted infections among HIVpositive patients usually suggest high risk sexual behaviors and HIV transmission to uninfected population. ${ }^{17}$ High-risk sexual behavior seems to be continually practiced among HIV-positive population..$^{12}$ To decrease associated morbidity and prevent the secondary spread of HIV and STIs, prevention efforts should focus on HIVpositive patients who continue to be engaged in high-risk sexual practices.

Corrections of high-risk behavior and STI management could decrease the risk of HIV transmission as it is reported that viral shedding in HIV-positive patients decreased significantly after the STIs were treated. ${ }^{18-20}$ A study on STI intervention with syndromic management in several populations in Mwanza has shown a successful reduction of HIV incidence by $38 \%{ }^{21}$

Until currently, there has been no study conducted on the prevalence of chlamydial infection in HIV-positive patients in Indonesia. Therefore, this study will be the first one that aims to determine the prevalence of chlamydial infection in male urethra and female cervix of HIV-positive patients in Indonesia.

\section{Methods}

\section{Study population}

This study was conducted at Teratai Clinic in Dr. Hasan Sadikin General Hospital, Bandung during the month of July 2012. Sexually active HIV-positive patients attending Teratai Clinic were offered to participate in this study. Eighty one HIV-positive participants (48 males and 33 females) were enrolled after written informed consent was obtained. Women having her menstrual period were excluded from the study.

The HIV serostatus of the study population was determined and confirmed before this study according to the National Guideline for HIV/ AIDS. Comprehensive data on characteristics and sexual history of the patients were collected through history taking and medical records. History taking, clinical examination, and specimen collections were conducted in Teratai Clinic, while the specimen processing was conducted in Biology Molecular Laboratory, Microbiology Department of Health Research Unit, Faculty of Medicine, Universitas Padjadjaran.

The study was approved by the Ethical Committee of Faculty of Medicine, Universitas Padjadjaran-Dr. Hasan Sadikin General Hospital Bandung.

\section{Specimen collection method}

Urethral swab of male patients and endocervical swab of female patients were collected using specimen collection kit (Roche) and transported to the laboratory in Chlamydia transport tubes (Roche), on the day of collection. At the laboratory, urethral and endocervical swab specimens for PCR assay were prepared immediately according to the instruction, frozen at $-20{ }^{\circ} \mathrm{C}$, and analyzed within 14 days of sampling.

\section{Specimen processing method}

The Roche Amplicor PCR Assay was used (the PCR was accomplished with thermocycler). After the amplification, the amplified nucleotide sequences were detected by an enzyme immunoassay and the optical density at wave length $450 \mathrm{~nm}$ was measured using a spectrophotometer. A positive result was defined as a reading above 0.5 while the result was considered equivocal when the reading is between 0.2 to 0.5 . A negative result was assigned for a reading below 0.2 . Statistical analysis was performed using SPSS 17.0

\section{Results}

During the study, 81 HIV-positive participants were screened for chlamydial infection. Among the 81 patients tested, 14 chlamydial infections were identified with 10 in male urethra and 4 in cervix. The prevalence of chlamydial infection in this study was $17.4 \%$. Meanwhile, the prevalence of urethral chlamydial infection in male was $20.8 \%$ and cervical chlamydial infection in female was $12.1 \%$.

A list of the $81 \mathrm{HIV}$-positive participants in this study is presented in Table 1. Male participants comprised $59.3 \%$ of the total participants and $69.1 \%$ participants were in $25-35$ years old group. Half of the participants were high-school graduates, $43.2 \%$ were self employed, and $55.6 \%$ were married.

Most of participants who were infected with Chlamydia was in the age group of 25-35 years old, with $17.9 \%$ of them were Chlamydia positive (Table 2). C. trachomatis was detected in $20.8 \%$ males and $12.1 \%$ females. Both single and divorced groups were infected with $C$. trachomatis as many as $27.8 \%$. This number is 
much higher compared to only $8.9 \%$ of married group that were infected by $C$. trachomatis.

Table 1 Baseline Characteristics of Participants

\begin{tabular}{|c|c|c|}
\hline Variable & $\mathrm{n}$ & $\%$ \\
\hline \multicolumn{3}{|l|}{ Age (yrs.) } \\
\hline$<25$ & 5 & 6 \\
\hline $25-35$ & 56 & 69 \\
\hline$>35$ & 20 & 25 \\
\hline \multicolumn{3}{|l|}{ Sex } \\
\hline Male & 48 & 59 \\
\hline Female & 33 & 41 \\
\hline \multicolumn{3}{|l|}{ Education } \\
\hline No education & 0 & 0 \\
\hline Elementary school & 4 & 5 \\
\hline Junior High school & 4 & 5 \\
\hline Senior High school & 41 & 51 \\
\hline College/university & 32 & 40 \\
\hline \multicolumn{3}{|l|}{ Occupation } \\
\hline Self employed & 35 & 43 \\
\hline Civil servant & 1 & 1 \\
\hline Working class & 20 & 25 \\
\hline Commercial sex worker & 1 & 1 \\
\hline Student & 1 & 1 \\
\hline Not working & 23 & 28 \\
\hline \multicolumn{3}{|l|}{ Marital status } \\
\hline Single & 18 & 22 \\
\hline Married & 45 & 56 \\
\hline Divorced & 18 & 22 \\
\hline
\end{tabular}

Table 3 shows that $17.9 \%$ participants with the age of sexual debut of less than 20 years old were infected with Chlamydia. This percentage is not significantly different from that of the participants with the age of sexual debut of more than 20 years old. There were $33.3 \%$ participants with 6 or more lifetime sexual partners were Chlamydia positive, which is higher when it is compared to only $14.3 \%$ participants with 1 lifetime sexual partners. Condom use behavior was also asked to the participants. Almost half of the participants included in the study admitted that they always use condom. Despite this statement, there were still $17.5 \%$ of the participants who were infected with Chlamydia. This means that we have to consider the participants' statement regarding condom use more carefully to understand the real condom use behavior.

Table 2 Characteristics of Participants with Positive C. trachomatis

\begin{tabular}{lccc}
\hline \multirow{2}{*}{ Variable } & \multicolumn{2}{c}{ C. trachomatis } & Total \\
\cline { 2 - 3 } & $(+)$ & $(-)$ & $\mathbf{n}$ \\
\hline Age (yrs.) & 1 & 4 & 5 \\
$<25$ & 10 & 46 & 56 \\
$25-35$ & 3 & 17 & 20 \\
$>35$ & & & \\
Sex & 10 & 38 & 48 \\
Male & 4 & 29 & 33 \\
Female & & & \\
Marital status & & 13 & 18 \\
$\quad$ Single & 5 & 41 & 45 \\
$\quad$ Married & 4 & 13 & 18 \\
$\quad$ Divorced & 5 & & \\
\hline
\end{tabular}

\section{Discussion}

The overall prevalence of chlamydial infection in this study was $17.3 \%$, which was higher than any of the previous studies. This is probably due to the fact that STI screening is not routinely performed for HIV-positive patients in Teratai Clinic. Since most of chlamydial infections are asymptomatic, most patients did not receive appropriate treatment and this could result in persistent chlamydial infection.

Several studies on prevalence of chlamydial infection using nucleic acid amplification test in HIV-positive patients have been conducted with varied results. A literature review of 37 clinical studies reported that chlamydia was the most common STI identified in HIV-positive patients, with $5 \%$ median prevalence, ranging from 3 to $10,9 \% .^{22}$

An evaluation on sexually active Inuit women living in remote villages in Alaska found that 114 (23\%) of 493 women had cervical infection with $C$. trachomatis. ${ }^{23}$ As shown in this study, it has been repeatedly demonstrated that in sexually active populations in which little diagnostic testing and/ or specific treatment is used, the prevalence of infection may reach surprisingly high levels. This reflects the asymptomatic nature of chlamydial infection and the ability of the infection, when untreated, to persist for months or years. ${ }^{23}$

Phipps reported that the prevalence of asymptomatic chlamydial infection in HIV- 
positive patients was $8.3 \%,{ }^{24}$ whereas Iwuji reported that the prevalence of chlamydial infection was $2.7 \%$ in asymptomatic patients and $19 \%$ in symptomatic patients. ${ }^{25}$

The prevalence of urethral chlamydial infections in male participants in this study was $20.8 \%$. The prevalence was higher than previous studies. Several authors reported varying result of $C$. trachomatis prevalence in HIV-positive men. The prevalence of chlamydial infection in HIVpositive men was $7 \%$ in India ${ }^{16}$ and America, ${ }^{15} 9 \%$ in England, ${ }^{25}$ and $6 \%$ in US army. ${ }^{26}$

In this study the prevalence was higher in men than women. This is probably due to the fact that most of the patients who came to Teratai Clinic are male, and compared to women, men have higher tendencies to engage in high risk sexual behavior. The risk for chlamydial infection was twice higher in men than women. ${ }^{26}$ This is probably due to higher risk sexual practices in men. Twenty nine point two percent of men admitted having more than 15 sexual partners, compared to $11.4 \%$ in women. ${ }^{27}$

A research in 11 cities in Indonesia showed that $33 \%$ of men had sex with female sex worker in the previous year and $20 \%$ with nonmarital female partners. This study also showed consistent condom use was low in both sex workers $(17 \%)$ and other non-marital partners $(13 \%){ }^{28}$ The prevalence of cervical chlamydial infections in female participants in this study was $12.1 \%$.

Previous studies have reported different results of chlamydial prevalence in HIV-positive women. ${ }^{18,29,30}$ The cervical chlamydial infection prevalence in women with HIV in 12 European countries was $11.8 \%{ }^{29}$ Research in Thailand found that the prevalence of chlamydial infection was $9.7 \%$ in HIV-positive woman. ${ }^{30}$ In an American study, it was reported that the prevalence of chlamydial infection was $3.6 \%$ in HIV-positive women. ${ }^{18}$

Chlamydial infection in HIV-positive patients were found as more common in female, but not statistically significant ${ }^{12}$ which was affirmed by another study showing a correlation between female sex and chlamydial infection in HIVpositive patients. ${ }^{31}$ Women have twice the risk of infected with C. trachomatis than men. This is probably because women are anatomically more vulnerable to STIs. Anatomic considerations make the transmission of STIs to women during sexual intercourse a biologically "more efficient" process. During intercourse, semen tends to pool in the vaginal vault causing prolonged contact with cervix epithelium. Another factor is cervical ectopy, which is commonly found in prepubertal women caused by hormonal changes. ${ }^{27}$
Norms regarding appropriate sexual behavior are usually more restrictive for women than for men in most societies. These norms not only limit women's sexual freedom but also restrict their access to information about sexuality. In addition, lack of economic independence may prevent women from leaving a relationship that puts them at risk for acquiring STIs. In many countries, wives have little control over marital sexuality and women's ability to negotiate safer sexual practices, particularly condom use, is practically none. $^{32}$

In this study, the average age of participants infected with C. trachomatis was 33.6 (34) years old, with a range of 23 to 71 years old. Most participants were in the age of 25-35 years old.

Most authors confirmed young age as a risk factor for chlamydial infection. ${ }^{11,18,31}$ Young age was significantly related to the risk for acquiring STI in HIV-positive patients. ${ }^{11}$ While another studies showed that an age of $<35$ years old with HIV positive were at risk of being infected with chlamydia. ${ }^{18,31}$ One study stated that the prevalence of chlamydial infection in $<25,25-$ 35 , and $>35$ years old were $6.3 \%, 4.8 \%, 1.9 \%$, consecutively. ${ }^{18}$

Several factors that contributed to young age as a risk factor for acquiring chlamydial infection include higher number of sexual partners ${ }^{15}$ and less concerns about the risk of contracting HIV which lead to inadequate use of protective measures despite knowledge of HIV-positive status. ${ }^{26}$ Onen reported that recent sexual activities decreased with increasing age which may be due to a number of factors, including partner availability, relationship satisfactory, social isolation, bereavement plus perceived ageism, and stigmatization. The presence of physical and medical illness can also impact sexual function and was a factor independently and negatively associated with recent sexual activity. ${ }^{15}$ Contrary to other studies, Iwuji found that age is not related with chlamydial infections in HIV-positive men. ${ }^{25}$

Most authors discovered that chlamydial infection is related with sexual behavior. It is also reported that high risk sexual behavior increased the risk for acquiring chlamydial infection significantly. ${ }^{33}$

Contrary to other studies, Lee found no significant relation between sexual behavior and STI incident in HIV-positive patients. ${ }^{11}$ This is probably due to bias. Many studies that observed sexual behavior frequently gave inaccurate result, because of recall and social desirability bias. $^{34}$

Sexual histories discussed in this study are age of sexual debut, number of sexual partners, 
Table 3 Sexual History of Participants with Positive $C$. trachomatis

\begin{tabular}{|c|c|c|c|}
\hline \multirow{2}{*}{ Variable } & \multicolumn{2}{|c|}{ C. trachomatis } & \multirow{2}{*}{$\begin{array}{c}\text { Total } \\
\mathrm{n}\end{array}$} \\
\hline & $(+)$ & $(-)$ & \\
\hline \multicolumn{4}{|l|}{ Age of sexual debut (yrs.) } \\
\hline$<20$ & 7 & 32 & 39 \\
\hline$\geq 20$ & 7 & 35 & 42 \\
\hline \multicolumn{4}{|c|}{ Number of sexual partner in the last month } \\
\hline 0 person & 6 & 21 & 27 \\
\hline 1 person & 6 & 42 & 48 \\
\hline$\geq 2$ persons & 2 & 4 & 6 \\
\hline \multicolumn{4}{|c|}{ Number of sexual partner in the last 3 months } \\
\hline 0 person & 4 & 16 & 20 \\
\hline 1 person & 7 & 39 & 46 \\
\hline$\geq 2$ persons & 3 & 12 & 15 \\
\hline \multicolumn{4}{|c|}{ Number of lifetime sexual partner } \\
\hline 1 person & 3 & 18 & 21 \\
\hline 2-5 persons & 4 & 35 & 39 \\
\hline$\geq 6$ persons & 7 & 14 & 21 \\
\hline \multicolumn{4}{|l|}{ Condom use } \\
\hline Never & 4 & 16 & 20 \\
\hline Seldom & 3 & 18 & 21 \\
\hline Always & 7 & 33 & 40 \\
\hline
\end{tabular}

condom use, and STI history. In this study, the average age of sexual debut in chlamydial infected participants is 19 years old, with 7 of 14 participants infected with $C$. trachomatis having sexual debut at the age of $<20$ years old. This result is in accordance with the results from a study by Ghosh who found the risk for acquiring chlamydial infection in HIV-positive patients increased in patients with age of sexual debut $<20$ years old. ${ }^{16}$

Young sexual debut, particularly in men is correlated with increased number of sexual partners, while in women this correlates with early marriage and sexual coercion. Sexual coercion is related to big age difference, infrequent condom use, and high STI risk. ${ }^{32}$ In this study, 6/27 of participants claimed not having sexual intercourse in the last month and $4 / 20$ in the last three months infected with $C$. trachomatis.

Fifty percent of homosexual and $22 \%$ women who admitted not having sexual intercourse in the last three months were infected with STI. ${ }^{34}$ This may be due to several reasons, including recall and social desirability bias in reporting ${ }^{34}$ and persistent chlamydial infection transmitted through sexual encounters $>3$ months before. ${ }^{15}$ Most of chlamydial infections are asymptomatic. Therefore, if routine screening was not done, most of infections would not be treated and could persist months or even years. ${ }^{23}$ Most of chlamydial infected participants in this study had $\geq 6$ lifetime sexual partners.

Several authors found that the number of sexual partners correlated with chlamydial infection. ${ }^{35,36}$ Findings show that increased number of sexual partners would increase the risk for acquiring chlamydial infection ${ }^{35}$ and $\geq 6$ sexual partners would increased the risk for acquiring chlamydial infection 13.5 times in women and 5.3 times in men. ${ }^{36}$

Most of participants in this study claimed always using condom in every sexual intercourse. Seventeen point five percent (7/40) of the participants who claimed that they always use condom were infected by C. trachomatis. Several authors reported conflicting results about condom use in chlamydial infection. ${ }^{11,34}$ One 
study found no correlation between condom use and incident of chlamydial infection ${ }^{11}$ while another study found that $20 \%$ of patients who always use condom were infected with STI. ${ }^{34}$ Most patients infected with Chlamydia claimed that they always use condom in the previous week..$^{35}$ This finding may be influenced by several factors, including recall and reporting bias, inconsistent and inappropriate condom use, ${ }^{33}$ or latent chlamydial infection. ${ }^{23}$

Contrary to other studies discussed above, van Benthem found that inconsistent condom use with casual sex partners increased the risk for acquiring chlamydial infection in HIV-positive patients. HIV-positive women who used condoms

\section{References}

1. Stamm WE. Chlamydia trachomatis infections In: Holmes KK, Sparling PF, Stamm WE, Piot P, Wasserheit JN, Corey L, et al., editors. Sexually transmitted diseases. $4^{\text {th }}$ ed. New York: McGrawHill; 2008. p. 575-94.

2. Global prevalence and incidence of selected curable sexually transmitted infections. Geneva: World Health Organization; 2001.

3. Young $H$, Moyes A, Horn K, Scott GR, Patrizio C, Sutherland S. PCR testing of genital and urine specimens compared with culture for the diagnosis of chlamydial infection in men and women. Int J STD AIDS. 1998;9(11):661-5.

4. Jespersen DJ, Flatten KS, Jones MF, Smith TF. Prospective comparison of cell culture and nucleic acid amplification tests for laboratory diagnosis of Chlamydia trachomatis infections J Clin Microbiol. 2005;45(10):5324-6.

5. Johnson RE, Green TA, Schachter J, Jones RB, Hook EW, Black C, et al. Evaluation of nucleic acid amplification testsas referencetests for Chlamydia trachomatis infections in asymptomatic men. J Clin Microbiol. 2000;38(12):4382-6.

6. Muhammad T, Ene C, Atanda G, Nwankwo A, Baba M. Seroprevalence of HIV infection among patients attending STD clinic at National Hospital Abuja, Nigeria. Sci Res Essays. 2009;4(2):65-8.

7. Global report UNAIDS report on the global AIDS epidemic. WHO; 2010.

8. Perkembangan HIV-AIDS di Indonesia triwulan III 2012 [Article on the Internet]. 2012 [cited 2013 Jan 25]. Available from: http: http://www. depkes.go.id/index.php/component/content/ article/43-newsslider/2186-perkembangan-hivaids-di-indonesia-triwulan-iii-tahun-2012.html. in less than $50 \%$ of their sexual contacts with casual partners had almost eight-fold higher risk and those who used condoms in $50-99 \%$ of the contacts had two-fold higher risk than women who did not have a casual partner. ${ }^{29}$

Based on the discussion in this paper, It is concluded that the prevalence of chlamydial infection in male urethra and female cervix of HIV-positive patients in Teratai Clinic, Dr. Hasan Sadikin General Hospital Bandung were 20.8\% and $12.1 \%$, consecutively, based on the PCR results. Identifying chlamydial infection using PCR assay should be considered for routine screening test in HIV-positive patients.
9. Wasserheit J. Epidemiological synergy: interrelationships between human immunodeficiancy virus infection and other sexually transmitted diseases. Sex Transm Dis. 1992;19(2):61-77.

10. Chan D. Fatal attraction: sex, sexually transmitted infections and HIV-1. Int J STD AIDS. 2006;17(10):643-50.

11. Lee HC, Ko NY, Lee NY, Chang CM, Liu SY, Ko W. Trends in sexually transmitted diseases and risky behaviour among HIV-infected patients at an outpatient clinic in Southern Taiwan. Sex Transm Dis. 2010;37(2):86-93.

12. Manning SE, Pfeiffer MR, Nash D, Blank S, Sackoff $J$, Schillinger J. Incident sexually transmitted infections among persons living with diagnosed HIV/AIDS in New York city, 2001-2002: a population-based assessment. Sex Transm Dis. 2007;43(12):1008-15.

13. Lawson L, Katzenstein D, Vermund S. Emerging biomedical interventions. In: Gibney L, DiClemente RJ, SH V, editors. Preventing HIV in developing countries. $1^{\text {st }}$ ed. New York: Kluker Academic; 2002. p. 43-66.

14. Fleming DT, Wasserheit J. From epidemiological synergy to public health policy and practice: the contribution of other sexually transmitted diseases to sexual transmission of HIV infection. Sex Transm Inf. 1999;75(1):3-7.

15. Onen NF, Schacham W, Stamm KE, Overton ET. Comparison of sexual behaviour and STD prevalence among older and younger individuals with HIV infections. AIDS Care. 2010;22(6):711-7.

16. Ghosh A, Dhawan B, Chaundry R, Vajpayee M, Sreenivas V. Genital mycoplasma \& Chlamydia 
trachomatis infections in treatment naive HIV-1 infected adults. Indian J Med Res. 2011;134(6):960-6.

17. Cohen M. Sexually transmitted diseases enchance HIV transmission: no longer a hypothesis. Sex Transm Dis. 1998;351(Sppl 3):5-7.

18. Page KR, Moore RD, Wilgus B, Gindi BA, Erbelding E. Neisseria gonorrhea and Chlamydia trachomatis among human immunodeficiency virus-infected women. Sex Transm Dis. 2008;35(10):859-61.

19. Cohen MS, Hoffman IF, Royce RA, Kaembe P, Dyer JR, Daly CC, et al. Reduction of consentration of HIV-1 in semen after treatment of uretritis: implications for prevention of sexual transmission of HIV-1. Lancet. 1997;349(9069):1868-73.

20. Ghys PD, Fransen K, Diallo M. The association between cervicovaginal HIV shedding, sexually transmitted diseases, and immunodupression in female sex worker in Abidjan, Cote d'Ivoire. AIDS. 1997;11(12):F86-93.

21. Mayer KH, Venkatesan C. Interactions of HIV, other sexually transmitted diseases, and genital tract inflammation facilitating local pathogen transmission and acquisition. Am J Reprod Immunol. 2011;65(3):308-16.

22. Kalichman SC, Pellowski J, Turner C. Prevalence of sexually transmitted co-infections in people living with HIV/AIDS: systematic review with implications for using HIV treatments for prevention. Sex Transm Infect. 2011;87(3):18390.

23. Toomey KE, Rafferty MP, Stamm WE. Unrecognized high prevalence of Chlamydia trachomatis cervical infection in an isolated Alaskan Eskimo population. JAMA. 1987;258(1):53-6.

24. Phipps W, Stanley H, Kohn R, Stansell J, Klausner JD. Syphilis, Chlamydia and Gonorrhoea screening in HIV-infected patients in primary care, San Fransisco, California, 2003. AIDS Patient Care and STD. 2005;19(8):495-8.

25. Iwuji CC, Reeves I, Nambiar K, Richardson D. Diagnostic utility of urethral smear in predicting urethral chlamydia in HIV-infected men. Int J STD AIDS. 2008;19(11):741-3.

26. Spaulding $A B$, Lifson $A R$, Iverson $E R$, Ganesan $A$, Landrum ML, Weintrob AC, et al. Gonorrhoea or chlamydia in a US military HIV-positive cohort. Sex Transm Infect. 2012;88(4):1-6.

27. Hook EW. Gender difference in risk for sexually transmitted diseases. Am J Med Sci.
2012;343(1):10-1.

28. Mustikawati DE, Morineau G, Nurhayati, Irmaningrum $\mathrm{Y}$, Riono $\mathrm{P}$, Prihutomo $\mathrm{S}$, et al. Sexual risk taking, sexually transmitted infections and HIV prevalence among four "high-risk" occupational froups of Indonesian men. Sex Transm Infect. 2009;85(5):391-6.

29. van Benthem BHB, Prins M, Larsen C, Delmas MC, Brunet JB, van den Hoek A. Sexually transmitted infections in european HIV-infected woman: incidence in relation to time from infection. AIDS. 2000;14(5):595-603.

30. Srifeungfung $S$, Roongpisuthipong $A$, Asavapiriyanont S, Lolekha R, Trbuddharat C, Lockpichart S, et al. Prevalence of Chlamydia trachomatis and Neisseria gonorrhoeae in HIV-seropositive patients and gonococcal antimicrobial susceptibility: an update in Thailand. Jpn J Infect Dis. 2009;62(6):467-70.

31. Chkhartishvili N, Dvali N, Khechiashvili G, Sharvadze L, Tsertsvadze T. High seroprevalence of Chlamydia trachomatis in newly diagnosed HIV patient in Georgia. Georgian Med News. 2010;2(189):12-5.

32. Buve A, Gourbin C, Laga M. Gender and sexually transmitted diseases. In: Holmes KK, Sparling PF, Stamm WE, Piot P, Wasserheit JN, Corey L, et al., editors. Sexually transmitted diseases. $4^{\text {th }}$ ed. New York: Mcgraw Hill; 2008. p. 151-64.

33. Venkatesh KK, van der Straten A, Mayer KH, Blanchard K, Ranjee G, Lurie MN, et al. African women recently infected with HIV-1 and HSV2 have increased risk of acquiring Neisseria gonorrhoeae and Chlamydia trachomatis in the methods for improving reproductive health in Africa trial. Sex Transm Dis. 2011;38(6):562-70.

34. Hamlyn E, Welz T, Rebaudengo S, Simms $H$, Poulton M. Sexual behaviour, condom use and rates od sexually transmitted infections in HIV clinic attendees in South East London. Int J STD AIDS. 2009;20(11):757-60.

35. Jin X, Chan S, Ding G, Wang H, Xu J, Wang G, et al. Prevalence and risk behaviour for Chlamydia trachomatis and Neisseria gonorrhoeae infection among female sex worker in an HIV/AIDS highrisk area. Int J STD AIDS. 2011;22(2):80-4.

36. Götz HM, van Bergen JEAM, Veldhuijzen IK, Broer J, Hoebe CJPA, Richardus JH. A prediction rule for selective screening of Chlamydia trachomatis infection. Sex Transm Infect. 2005;81(1):24-30. 